\title{
Territorio, territorialidad y región metropolitana en un marco de producción flexible
}

\begin{abstract}
This article discuss some conceptual and methodological questions about flexible production, territory and territoriality, from the analysis of the logics and strategies of a self-driven transnational company on the territory. The study case is Daimler-Chrysler Argentina company, located in the Metropolitan Region Córdoba. The hypothesis that leads this study is that the implementation of flexible production generates, in the peripheral areas like the one considered here, "glocaldependent" territories.
\end{abstract}

Keywords: flexible production, territory, territoriality, self-driven industry, Córdoba Metropolitan Region.

\section{Resumen}

En este artículo se discuten algunas cuestiones conceptuales y metodológicas en torno a la producción flexible, el territorio y la territorialidad, desde el análisis de las lógicas y estrategias de una empresa transnacional automotriz sobre el territorio. Para ello se toma como caso de estudio la empresa Daimler-Chrysler Argentina, localizada en la Región Metropolitana Córdoba. La hipótesis que guía este trabajo sostiene que la implementación de la producción flexible genera, en ámbitos periféricos como el considerado por este estudio, territorios "glocaldependientes".

Palabras clave: producción flexible, territorio, territorialidad, industria automotriz, Región Metropolitana Córdoba. 


\section{Introducción}

$\mathrm{L}$ a nueva división territorial del trabajo a escala global, a partir de los años ' 70 , ha generado en los ámbitos periféricos una lógica territorial glocaldependiente. En ella, la desigualdad emergente da lugar a un diálogo contrastado, en un territorio fragmentado por el proceso de reestructuración económico-social en el contexto de la globalización. Esta "comunicación incomunicada" (valga la paradoja) se produce en el territorio entre agentes sociales que, a partir de posiciones distintas y bajo condiciones diferentes, quedan incluidos o excluidos del proceso de globalización. Así, el impacto territorial derivado de la localización de determinadas actividades económicas en ámbitos periféricos, producto de esta nueva división territorial, produce mutaciones territoriales que es necesario revisar.

En este sentido, las reformas económicas de la década del 90' han sido significativas en Argentina, en tanto la cristalización del modelo económico neoliberal produjo un giro en la estructura socioeconómico-territorial. En relación a la actividad económica industrial, este proceso transcurre simultáneamente con la transición del modelo de industrialización fordista al posfordista, por supuesto con las características singulares que dichos modelos pueden adquirir en un ámbito periférico. El paso de un modelo a otro se dio a partir de la consideración de Argentina como mercado emergente en el contexto de la conformación del MERCOSUR, y dentro del cual Córdoba tiene una posición estratégica de localización (Mapa 1). En el análisis que aquí se propone, dicho paso ha significado, por los impactos socioterritoriales detectados empíricamente, la emergencia de un mercado sumergente para la sociedad.

La aplicación del modelo de industrialización posfordista planteó un conjunto de nuevas interrelaciones entre territorio, tecnología, trabajo y capital con relación al espacio industrial, que permi-

* Investigadora de SECyT/PROGEO. Facultad de Filosofía y Humanidades, Universidad Nacional de Córdoba, Argentina. E-mail: claudiatomadoni@hotmail.com.

"* Recibido el 22 de mayo de 2002, aprobado el 7 de febrero de 2003. ten afirmar que se produjo un proceso de reestructuración industrial. Estas interrelaciones se pueden interpretar a través de diversos ejemplos. Un ejemplo paradigmático, por lo que implica en la generación del producto geográfico bruto de un territorio, puede ser la consideración de las actividades en torno a la industria automotriz. Por esta razón, algunos ejemplos relativos a dichas interrelaciones a nivel de empresas automotrices, localizadas en la Región Metropolitana Córdoba (RMC) durante la década del '90, pueden dar cuenta del proceso de reestructuración mencionado.

En el caso de las empresas transnacionales automotrices, la reestructuración cristaliza en una sustitución de estrategias con cambios de lógica localizacional, implementación de innovaciones tecnológicas y organizacionales y generación de flexibilización laboral. La puesta en práctica de esta modalidad de accionar generó un territorio en red de características singulares, a la vez que produjeron impactos empresariales y extra-empresariales que ponen en evidencia una gran contradicción: quien teje la red no tiene puesto su interés en el desarrollo del territorio en cual se asienta la red. Por el contrario, el interés está puesto en la reproducción ampliada del capital transnacional a partir de un mercado considerado emergente, como el MERCOSUR.

En consecuencia, este territorio adquirió dimensiones que es necesario examinar, para que quienes deban operar en su gestión tengan herramientas sustentadas en conocimientos construidos científicamente, en la medida que el resultado de este cambio de lógica produjo, contrariamente a lo esperado por algunos agentes locales, un proceso de desindustrialización del tejido industrial. El resultado del proceso es un territorio que se caracteriza por no cumplir con ninguno de los requisitos para una eventual relocalización y reactivación industrial, a saber: mercado, seguridad, vías de comunicaciones suficientes y eficientes, sustentabilidad ambiental, estabilidad económica, social y política y calificación de mano de obra. Más allá del hecho que algunos aún creen que estas cuestiones aún sobran, desde una posición que responde al legítimo orgullo de lo que fue el territorio antecedente/condición de este proceso, pero las evidencias recogidas están indicando que de no promoverse estrategias articuladas entre los diferentes agentes sociales, el territorio conse- 
Mapa 1. Ubicación de Córdoba en el corredor del MERCOSUR.

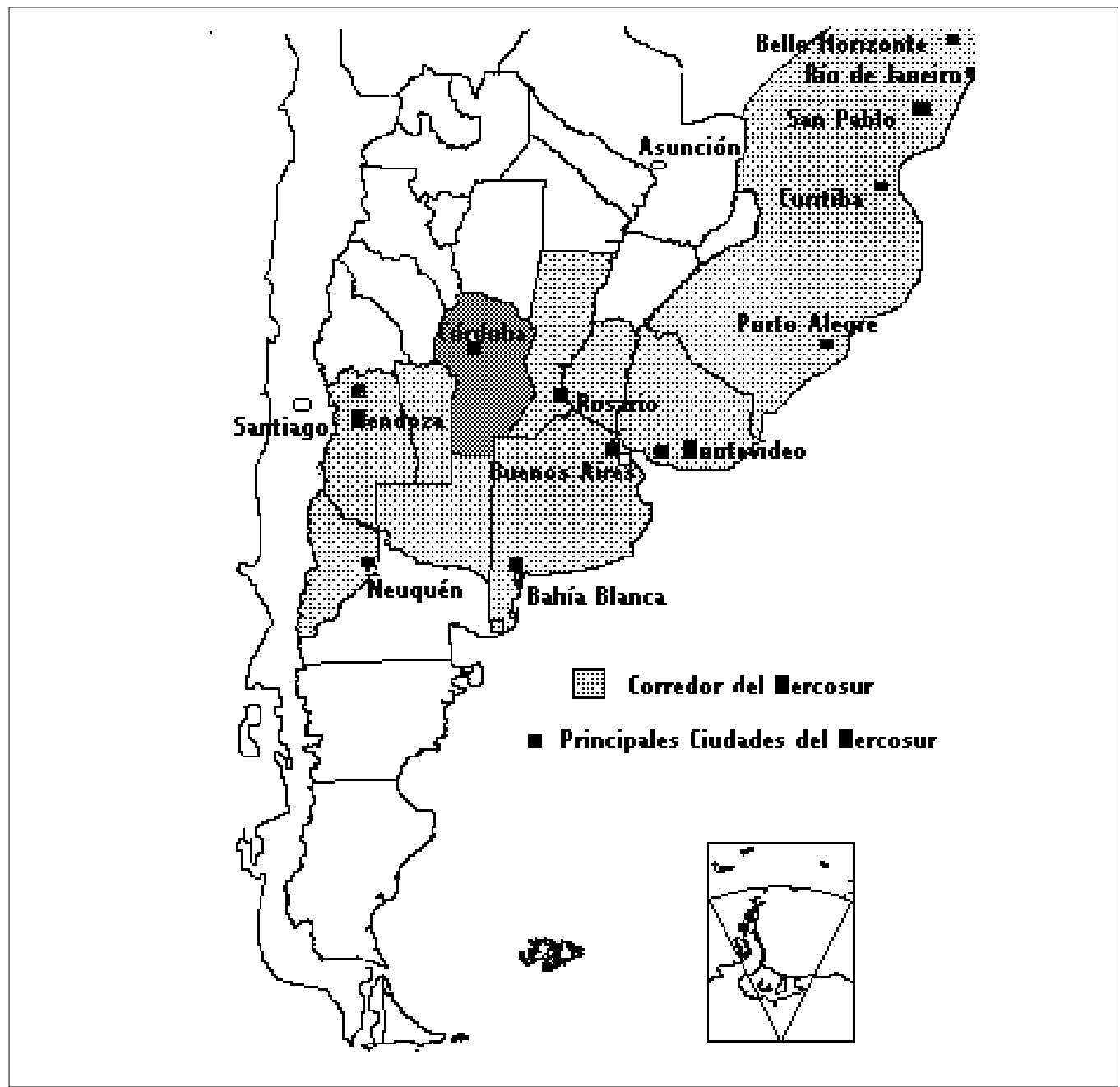

Fuente: elaboración propia.

cuente del proceso de reestructuración estaría en un franco problema de sustentabilidad.

Cabe entonces preguntarse qué fue lo que sucedió: ¿ por qué el territorio antecedente derivó en un territorio consecuente de características insustentables? A partir de los años 90' se asiste a una nueva lógica territorial de carácter glocaldependiente, en tanto que las empresas transnacionales diseñaron estrategias globales de segmentación productiva con diversificación de riesgo y jerarquización territorial que, acompañadas por estrategias locales de atracción de capitales por parte del gobierno y avaladas por un accionar sindical de corte autorreproductivo, generaron una situación dependiente para los agentes individuales (trabajadores) como para las ciudades y sus regiones metropolitanas, lugares donde se produce el "juego de los agentes".

Teniendo en cuenta estos antecedentes, los objetivos del presente artículo son: (a) explicitar algunas cuestiones conceptuales y metodológicas en torno a producción flexible, territorio y territorialidad; (b) caracterizar el proceso de reestructuración productiva acaecido en la RMC; (c) analizar el impacto de la producción flexible del sector automotriz en el territorio de la RMC; y (d) examinar el caso DaimlerChrysler. 
Los resultados aquí expuestos surgen de información proveniente de entrevistas en profundidad realizadas a informantes claves, observaciones in situ en hogares de trabajadores, empresas y lugares próximos a éstas y consulta a instituciones involucradas (sindicatos, asociaciones empresarias y organismos gubernamentales). La confrontación y análisis de la información recopilada deja al descubierto las coincidencias y contradicciones que develan la trama oculta de relaciones que subyace a un aparente proceso de reestructuración y sus repercusiones en el territorio.

\section{Consideraciones teórico-conceptuales}

\subsection{La producción flexible: la nueva cara del tiempo y el espacio}

La producción flexible es una nueva forma de producir, característica del modo de acumulación posfordista en el contexto del capitalismo global. Las nuevas tecnologías en materia de informática y telecomunicaciones son un factor coadyuvante en su emergencia, así como las condiciones de competencia impuestas por mercados cada vez más segmentados y desregulados. La producción flexible supone, desde el punto de vista estrictamente productivo, series cortas con breve ciclo de vida de los productos y diversificación de los mismos de acuerdo a los requerimientos cambiantes del mercado. La competencia interempresarial se impone y ello implica una mayor tasa de innovación para dar respuesta rápida, a bajo costo y sin acumulación de stocks improductivos, por lo cual la producción es ajustada a tiempo (just in time). En este esquema productivo, la diversificación del riesgo es un elemento clave para reducir costos; de allí la descentralización productiva a través de un proceso de terciarización (outsourcing) de actividades.

Desde el punto de vista territorial, la producción flexible supone a escala global una nueva división territorial del trabajo, efectivizada en la relocalización de empresas transnacionales en aquellos lugares con buena oferta de ventajas competitivas. De este modo, emerge un proceso de competitividad entre los territorios para captar posibles inversiones, situación que deriva a escala local, cuando se "gana la partida", en una reindustria- lización con concentración de actividades y establecimientos. En este proceso cobran protagonismo tanto las pequeñas y medianas empresas locales como aquellas transnacionales, que fungen como proveedoras de las empresas ensambladoras que segmentan su producción hacia ellas. Ello no obstante, la conexión en red para operar permite "unir" territorialmente lo que se produce en diversos lugares y con el más bajo costo.

La especialización flexible se produce tanto en productos como en procesos y da cuenta de una estructura productiva que -sin quebrarse, y adaptándose a las necesidades de quien la maneja- cambia de forma con acelerada velocidad, con la intención de producir para un mercado que, paradójicamente, al mismo tiempo contribuye a diversificar y achicar. La diversificación se visualiza en el incremento de oferta de productos y en las nuevas estrategias de venta a plazo que incentivan el consumo. Pero paralelamente, son las mismas empresas las que, al reducir costos mediante la precariedad laboral, reducen el mercado de consumo que intentan incrementar.

\subsection{Mercado de trabajo, tecnología y flexibilidad}

Un concepto directamente relacionado con la paradoja mencionada es el de mercado de trabajo, ámbito fuertemente reconvertido para hacer lugar a la flexibilidad del nuevo modo productivo, en el cual las tecnologías son un factor coadyuvante del proceso de reestructuración del capital. La tecnología como factor supone un conjunto de conocimientos y métodos, incorporados tanto a procesos como a productos. En el primer caso, hablamos de "tecnologías blandas" que permiten elevar la rapidez y la precisión de los procesos, reduciendo costos al capital; y en el segundo, se alude a "tecnologías duras" que permiten mejorar la calidad y diferenciación del producto. En ambos casos, su utilización se relaciona con el factor trabajo en términos de condición y no de determinación.

Por su parte, el trabajo puede ser definido como cualquier esfuerzo para conseguir un fin económico relacionado con la reproducción social. En este sentido, es diferente al concepto de fuerza de trabajo, que alude a la capacidad natural del hombre de desarrollar una actividad; ahora bien, cuando parte de 
esa fuerza de trabajo se pone en venta en el mercado, es decir, se mercantiliza y se la retribuye con un salario, es cuando hablamos de empleo y de la constitución de un mercado de trabajo, desarrollado en el marco de formas institucionales que concurren en la configuración de un determinado régimen de acumulación y de acuerdo con especificidades sociales, temporales y territoriales.

Al respecto Castel (1997), encarando la problemática del trabajo no como relación técnica de producción sino como soporte privilegiado de inscripción en la estructura social, construye metafóricamente "zonas" de cohesión social a partir del ingreso o no al mercado de trabajo. Así, la asociación trabajo estable - inserción relacional sólida, caracteriza una zona de integración. A la inversa, la ausencia de participación en actividades productivas produce exclusión y una zona de desafiliación. La vulnerabilidad social será la característica de la zona intermedia e inestable que se conjuga a partir del establecimiento de condiciones de trabajo precario y aleatorio.

Otros enfoques abordan la relación entre tecnología y empleo coincidiendo en señalar el efecto negativo de las nuevas tecnologías de la informática y telecomunicación en la generación de desempleo tecnológico. En esta dirección, Rifkin (1996) argumenta que "nuevas y más sofisticadas tecnologías informáticas basadas en la información y en el empleo de ordenadores llevarán a la civilización a situaciones cada vez más próximas a la desaparición del trabajo" (17). La crítica apunta a señalar que las nuevas tecnologías ayudan a sustituir trabajo por capital contribuyendo a elevar el nivel de ganancia de las empresas, señalando asimismo que los empleos generados por las nuevas tecnologías no son suficientes para absorber el desempleo producido, y que los nuevos empleos, sobre todo de mandos medios, decrecen a medida que avanza una mayor incorporación de tecnología en las empresas, por lo que la brecha entre empleo y desempleo es cada vez mayor.

En un reciente trabajo, Sennett (2000) profundiza la crítica a la actual situación del mercado de trabajo a través de un análisis comparativo entre el ámbito de trabajo rígido, en vías de desaparición, y el de trabajo flexible, impuesto por el capitalismo flexible de la "Corte de Davos". Su análisis alude a las nuevas condiciones laborales y sus consecuencias opresoras sobre las personas. Comienza su reflexión recordando la definición del término "flexibilidad", y señala que el mismo designa la capacidad de un árbol para ceder y recuperarse implicando, a la vez, su puesta a prueba y la restauración de su forma. Así, el autor indica que "en condiciones ideales, una conducta humana flexible debería tener la misma resistencia a la tensión: adaptable a las circunstancias cambiantes sin dejar que éstas lo rompan". No obstante, "las prácticas de la flexibilidad se centran principalmente en las fuerzas que doblegan a la gente" (Sennett, 2000: 47). Este doblegamiento opera a nivel colectivo y se evidencia en las nuevas condiciones laborales imperantes en los mercados de trabajo, que al generar incertidumbre, ausencia de confianza y compromiso con raíces profundas, superficialidad del trabajo en equipo y -más que nada- el fantasma de no conseguir nada por uno mismo en el mundo (y de tampoco poder "hacerse" una vida mediante el trabajo), derivan en una consecuencia no deliberada por el capitalismo: el valor del lugar y el deseo de comunidad. Así, se enfatiza que "el lugar tiene un poder, y es posible que ese poder imponga restricciones a la nueva economía” (Sennett, 2000: 144-145).

Ahora bien, si el empleo es fuerza de trabajo puesta en el mercado, obviamente las formas que adquieran los procesos productivos, en este caso la producción flexible, afectarán el desenvolvimiento de dicho mercado y cuajarán en el territorio de manera diferenciada. Esta conjugación conceptual impone definir la noción de territorio, en la medida que si consideramos la afirmación de Sennett relativa al valor adquirido por el "lugar", se podrían encontrar herramientas conceptuales de importancia para interpretar los efectos nocivos del paradigma flexible en el trabajo.

\subsection{Territorio y territorio "glocaldependiente"}

El territorio es un constructo social en determinadas coordenadas de espacio-tiempo. Ya se ha caracterizado al territorio de la RMC como un ejemplo de "territorio glocaldependiente". Con este neologismo se alude a una característica distintiva de dicho territorio: la emergencia de una nueva lógica territorial, producto del proceso de reestructuración productiva en la década del '90 en Argentina. El 
neologismo "glocaldependiente" se forma a partir de la contracción de los términos "global" y "local", a lo cual se agrega el calificativo de dependiente. Con esta construcción se pretendía expresar las prácticas de los agentes sociales involucrados en la emergencia de esta nueva lógica territorial. Lo global aludía a las estrategias diseñadas por las empresas; lo local a las estrategias trazadas por los gobiernos; y lo dependiente se refería a la situación del trabajo con relación a las estrategias de empresas y gobierno (Tomadoni, 2000).

Sin embargo, es necesario avanzar y mejorar el alcance del concepto construido. La noción de territorio refiere en un sentido más acabado a la relación dialéctica entre forma y contenido, es decir, entre configuración territorial y dinámica social (Santos, 1986). En el caso considerado, esa relación se plantea, respectivamente, entre el nuevo paisaje industrial metropolitano emergente de la reestructuración productiva -constituido por lo natural y lo social adicionado a él-y el juego de estrategias de los agentes sociales, componente este último que hasta el momento primaba en la definición de territorio. Ahora bien, esta relación se complejiza aún más cuando se incorpora la dimensión temporal al análisis para considerar la génesis del proceso. Así, se asiste a la conformación de una relación, no ya dialéctica entre espacio y sociedad, sino -al decir de Soja (1997)- trialéctica, entre sociedad, espacio y tiempo.

Realizadas estas explicitaciones conceptuales, nada más enriquecedor ahora que considerar casos que puedan dar cuenta de la conformación de esta nueva lógica territorial. En consecuencia, y a través de una indagación empírica de carácter principalmente cualitativo, se toma como leading case la industria automotriz.

\section{Consideraciones teórico- contextuales}

\subsection{La industria automotriz en Argentina y en la RMC: localizaciones, estrategias y marco regulatorio}

En la década del ' 50 comienza en Argentina a desarrollarse como parte del proceso de la política de sustitución de importaciones la industria auto- motriz. Sin embargo, su historia se podría comenzar a bosquejar antes de este proceso, y se puede dividir en cinco períodos: preindustrial (1910/1914-1954); conformación y afianzamiento del espacio industrial (1954-1975); crisis y primera apertura trunca (1975-1990); reestructuración y segunda apertura (1991-1998) (Tomadoni, 1999); y crisis y desarticulación del espacio industrial (1999-2003) (Tomadoni, 2004).

Durante el primer período se sientan los precedentes del espacio industrial automotriz, mientras que en el segundo y tercero se desarrolla un espacio industrial automotriz de tipo fordista, que por sus peculiaridades es denominado como fordismo idiosincrásico dependiente (Gatto, 1990). El cuarto período, con una producción de tipo flexible, ocurre en un contexto de reestructuración económica en el marco del MERCOSUR, como espacio regional de acumulación para las transnacionales que se sitúan en Argentina y Brasil. Finalmente, el período actual es el de crisis con continuidad del tipo de producción flexible, en el cual el MERCOSUR se ha consolidado como mercado de acumulación para las transnacionales.

Históricamente la industria automotriz se ha localizado en cuatro provincias argentinas: Buenos Aires, Córdoba, Santa Fe y Tucumán, siendo las regiones metropolitanas de las dos primeras las de concentración por excelencia de la actividad. A nivel de empresas ensambladoras se localizan en la década del '90 en Buenos Aires VW, Ford, Peugeot, Toyota, Mercedes Benz y El Detalle; en Córdoba, Renault, Fiat, GM, Chrysler, Iveco, Nakai y Marco Polo, esta última en el departamento Río Cuarto; en Rosario (provincia de Santa Fe), General Motors, y en la provincia de Tucumán, Scania.

En este marco, y a escala nacional, puede decirse que entre 1993-1998 la producción de las ensambladoras automotrices aumentó un 34\%, pasándose de producir 342.000 vehículos en 1993 a 458.000 en 1998 . Este perfil tiene su origen en un incremento de las exportaciones del orden de $700 \%$ principalmente hacia Brasil, donde las mismas pasaron de 30.000 unidades en 1993 a 240.000 en 1998 (INDEC, 1999).

Estos cambios se operan a partir de un régimen legal especial decretado para el sector en 1991 que 
Mapa 2. Ciudad de Córdoba y localidades de la RMC vinculadas por actividad automotriz.

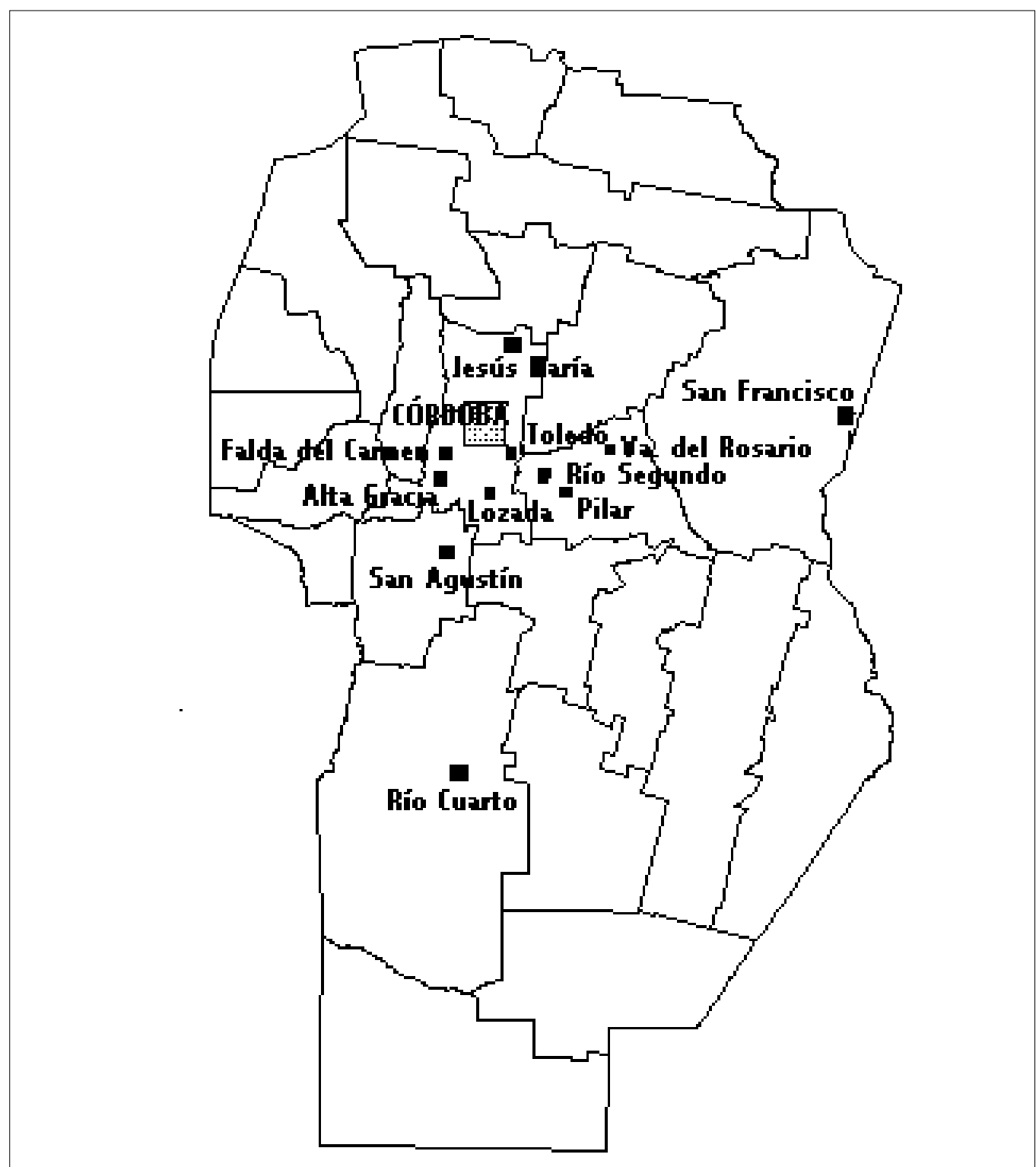

Fuente: elaboración propia.

favorece en gran medida a las empresas automotrices, pues permite consolidar la estrategia de ensamblaje de partes importadas. Entre otras cuestiones, este decreto promueve un incremento del $20 \%$ al $40 \%$ de la proporción de insumos importados para ensamblar los vehículos, el cual se establece a través de una rebaja del $10 \%$ al $3 \%$ en el pago de los impuestos para importar autopartes. Esta situación se agudiza a comienzos de 1996, cuando en nuevas negociaciones con Brasil se establece la exclusión del cupo de importación para el comercio intra-zona y se elimina el arancel para el ingreso de autopartes originarias del MERCOSUR, lo cual impulsó el abaratamiento relativo de los insumos, dadas las mayores facilidades de importación. La situación empeoró para las empresas radicadas en Argentina cuando, a comienzos de 1999, Brasil decidió devaluar su moneda. Esta decisión unilateral asestó un gran golpe a la economía argentina, especialmente al sector automotriz. En este punto se debe señalar la dificul- 
Figura 1. Producción automotriz de empresas ensambladoras localizadas en la RMC.

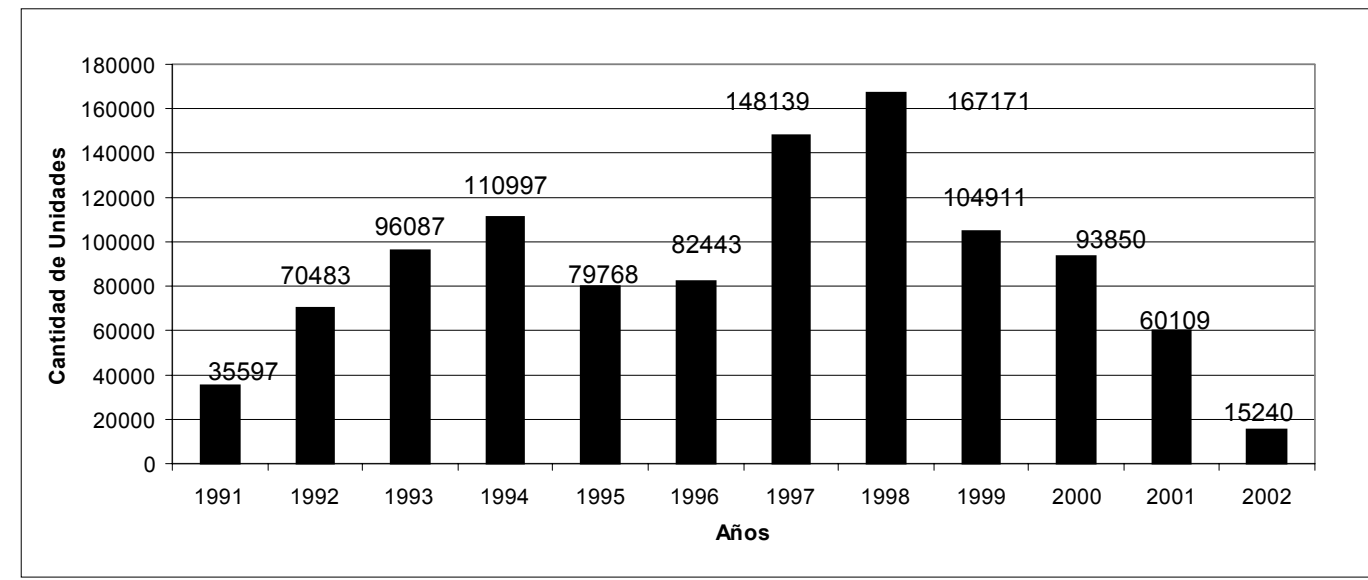

Fuente: elaboración propia en base a datos de ADEFA.

tad que ha significado la falta de convergencia entre los estados miembros del MERCOSUR, en términos de política macroeconómica en general y de política monetaria en particular.

Caducado el régimen del año 1991, y después de arduas discusiones, en marzo de 2000 los gobiernos de Argentina y Brasil acordaron lo que ha dado en llamarse Política Automotriz Común (PAC), mediante la cual se define un nuevo régimen automotriz de transición hasta 2006, año en que comenzaría a regir un libre comercio de vehículos entre los países firmantes. La PAC prevé un régimen de intercambio compensado y la integración nacional del $30 \%$ de los autos, con un 30\% de autopartes del MERCOSUR y un $40 \%$ de autopartes extrazona como máximo (Tomadoni, 2004).

En este contexto, la ciudad de Córdoba jugó un papel protagónico. Con una población de 1.276.814 habitantes, la ciudad ocupa el segundo lugar en el rango jerárquico del sistema urbano argentino después de Buenos Aires, no sólo por su cantidad de población sino por su dinámica económica. Esta ciudad es el nodo central de una región metropolitana que, en relación a la industria automotriz, se define por la participación de una serie de localidades en las cuales se localizan empresas autopartistas y población que nutre históricamente de trabajadores a las mismas (Mapa 2).

En el caso de Córdoba, y al promediar la década del ' 90 , la actividad automotriz representa el sector industrial más dinámico de la economía, correspondiéndole buena parte de la generación del producto geográfico bruto de la Provincia de Córdoba, que para el año 1997 se calculó en \$20.140.079.129 ${ }^{1}$, correspondiéndole al departamento capital (donde se localiza la ciudad de Córdoba) la cifra de $\$ 7.921 .410 .351$.

Es interesante revisar la "respuesta local" de la RMC ante la llegada de inversiones transnacionales en la década del 90', en la medida que luego de un proceso de despegue y crecimiento del sector automotriz, el sector se encuentra actualmente en una profunda crisis, tanto a escala local metropolitana como nacional (Figura 1). No se debe atribuir esta crisis sólo a la rígida economía de la convertibilidad que restó competitividad a los esfuerzos empresarios, como aducen las argumentaciones neoliberales, sino que hay que explicar en función de un modelo de producción que contribuyó a achicar el mercado al cual estaba dirigida su producción. Este logro tan contradictorio se generó con producción flexible y precariedad laboral.

Las ensambladoras automotrices localizadas en la RMC se desarrollan sobre la base de estrategias globales, básicamente de integración vertical (Méndez \& Caravaca, 1996), y directamente relacionadas con la participación de Argentina en el MERCOSUR.

${ }^{1}$ Según la ley de convertibilidad del año 1991, la relación de cambio establecida era un peso por un dólar. 
En este marco, la ciudad de Córdoba contaba con una trayectoria automotriz desde los años '50, tal como lo demuestran diversos trabajos (Gatto, 1990; Novick \& Yoguel, 1998; Cecchetto, 1988; 1990; Nazareno, 1991), por lo que la abundancia y calificación de la mano de obra, la existencia de economías de escala, la presencia de universidades y escuelas técnicas, la existencia de servicios a la producción, la infraestructura vial y su posición geoestratégica en relación al MERCOSUR fueron factores que primaron en el criterio de localización de las empresas.

A estas ventajas deben sumarse las excepciones impositivas y las ayudas fiscales ofrecidas por el gobierno. Cabe destacar que junto con las ensambladoras transnacionales arribaron también transnacionales autopartistas como VW, Magneti Marelli, Ferrosider, Comau, Maxion, Polymont, Delfhi Automotive Systems y Hartman Automotive, entre otras. Así, la industria automotriz se desarrolla en un régimen formulado de manera muy favorable a las grandes empresas transnacionales, $\mathrm{y}$ acorde con sus estrategias globales, en las cuales la conformación del MERCOSUR es considerado un espacio regional de acumulación. Estas empresas han sido las que han protagonizado el relanzamiento del sector automotriz con características posfordistas o "toyotistas" en la década del 90’ en Argentina.

\section{Territorio, territorialidad y producción flexible}

El derrotero estratégico desplegado por las empresas transnacionales automotrices excede ampliamente los límites de un territorio, tanto por sus implicancias productivo-comerciales como por sus impactos socioterritoriales. Las decisiones tomadas en un lugar lejano impactan en otro lugar, próximo por tecnología e impresionantemente cercano en los términos más cotidianos del hombre común.

Ante estas circunstancias, se debe señalar ciertas limitaciones en la consideración de una región metropolitana como territorio de análisis con respecto a la actividad industrial automotriz. En general, todas las empresas del rubro describen en su juego productivo-comercial una territorialidad propia que no incluye a localidades que, desde otras actividades y consideraciones, sí pueden señalarse como funcionalmente integradas a una región metropolitana $^{2}$. Por ejemplo, a escala de la RMC las empresas automotrices tienen en la década del ' 90 una fuerte presencia, pero sus juegos exceden ampliamente la región, trasvasando su accionar a diferentes escalas. En consecuencia, para dar cuenta de la expresión territorial de la industria automotriz a partir de lo ocurrido en la RMC, es necesario recurrir a una categoría de análisis que permita mostrar el juego a muy diferentes escalas, y de manera particularizada de acuerdo al accionar de cada empresa. Así, DaimlerChrysler describe una territorialidad diferente a la de Fiat, de Renault o de VW; cada empresa construye una estrategia territorial, y en ella la RMC es un eslabón más. En estos términos, se podría hablar de un territorio de la industria automotriz cuya territorialidad se expresa acorde al accionar de estas empresas que operan no sólo a escala local, es decir de la $\mathrm{RMC}$, sino también a escala nacional en Argentina, a escala macrorregional en el MERCOSUR y a escala internacional en lo que ha dado en llamarse extrazona MERCOSUR.

Acaso resulte necesario detenerse un momento y señalar que la noción de territorialidad es entendida como estrategia territorial de un individuo o grupo en el intento de acceder al control de personas, cosas y relaciones sobre un área geográfica delimitada que se configura como territorio (Sack, 1986). En estos términos, la territorialidad, es decir las estrategias construidas por diferentes agentes sociales para apropiarse de un lugar, resultan de un juego deliberado e intencionado que involucra una lógica propia de la sociedad que construye esa territorialidad, sociedad que contiene tanto a quienes ejercen el poder para acceder al control del territorio como a quienes posibilitan ese dominio. Es decir, la territorialidad se construye socialmente, y es en consecuencia una expresión territorial que adopta el poder a través del ejercicio de estrategias territoriales y no territoriales.

\footnotetext{
${ }^{2}$ Esta integración es objeto de estudio de un equipo de investigación del Instituto de Investigación y Formación en Administración Pública (IIFAP) de la Universidad Nacional de Córdoba, dirigido por Claudio Tecco y Juan Carlos Bressan, bajo el título "Región Metropolitana Córdoba: un estudio del sistema urbano y de su vinculación a la red de ciudades del Cono Sur (2001-2003)".
} 
Acorde con lo señalado, la territorialidad construida por las empresas, en función del rediseño de sus estrategias productivo-comerciales globales, podría interpretarse en términos de región. El concepto de región, de fuerte entidad geográfica, serviría en el caso de la industria automotriz- para aglutinar objetos geográficos, agentes sociales y las relaciones entre ambos en un territorio a muy diferentes escalas, que se caracteriza paradójicamente por su contigüidad y por su discontinuidad.

Esta contigüidad puede ser entendida en términos de proximidad a otras empresas para el funcionamiento según el criterio del just in time, y es aquí donde aparece la región metropolitana como territorio preferencial en la lógica industrial automotriz; por su parte, la discontinuidad obedece al proceso de segmentación productiva del modelo de producción flexible, que aprovecha las ventajas competitivas ofrecidas por diferentes territorios en el mundo. La territorialidad resultante configura el territorio de la industria automotriz, que por su conformación multiescalar es preciso interpretar en términos territoriales de región. Y no de cualquier tipo de región, sino de una región virtual ${ }^{3}$ caracterizada por una configuración contractual; una estructura complementaria; una construcción selectiva; un tipo de planificación táctica; un proyecto regional coyuntural; una espacialidad discontinua; una motivación societal de competencia; una temporalidad pactada; y una descentralización funcional (Boisier, 1994).

Ahora bien, recordemos que el territorio es una construcción social en el tiempo y espacio y aglutina

\footnotetext{
${ }^{3}$ Boisier (1994), echando por tierra una serie de presupuestos sobre la noción de región y considerando que la flexibilidad, la elasticidad y la colapsabilidad son requisitos indispensables para comprender el funcionamiento de las regiones en la época de la globalización, propone tres tipos de regiones, a saber: las regiones pivote, las regiones asociativas y las regiones virtuales. Las primeras responden a territorios organizados de manera compleja e identificable a escala de división político-administrativo histórica; las segundas se conforman a partir de la voluntad de unión de varias regiones adyacentes; y las terceras son resultado de un acuerdo contractual, formal o no, entre dos o más regiones pivotales o asociativas. Es importante aclarar que no se comparte con el autor la idea de considerar a las regiones como sujetos. Las regiones son objetos y los agentes que en ella operan son los encargados de dar dinámica a ese territorio. La región por sí sola no tiene vida, la vida se la otorgan las prácticas de sus agentes.
}

objetos de diferente naturaleza (carreteras, puertos, ríos, barrios obreros, establecimientos productivos, parques industriales, etc.), otorgando "forma" a un paisaje que adquiere toda su dinámica en el juego dialéctico con el "contenido", es decir, con la sociedad que le da sentido y significación. Este territorio, porción de espacio y tiempo en determinadas coordenadas, tiene una dinámica particular y emerge relacionado a diferentes escalas con otros territorios, que contiguos o discontinuos se concretan territorialmente en una región de mayores dimensiones que la región metropolitana de la cual es tributaria. Este tipo de configuración territorial obviamente adquiere geometrías variables consonantes con el indicador a considerar, en este caso las estrategias territoriales y no territoriales de empresas automotrices. Haciendo un paréntesis como para ordenar ideas, digamos que un territorio es una porción de espacio-tiempo y que las relaciones entre territorios dan forma a una región. En este sentido, la noción de región es de carácter relacional.

No obstante, y retomando la idea de la región virtual, se puede afirmar que la industria automotriz, como actividad inherente y paradigmática del capitalismo, se apropia del valor de uso complejo de las regiones metropolitanas donde localiza principalmente sus actividades, y las incorpora al tejido en red de una gran región de tejido reticular impulsada por la ideología de la competitividad y flexibilidad de la industria automotriz globalizada. Así, la territorialidad construida por estas empresas da cuenta de una región virtual conformada principalmente por varias regiones metropolitanas y por lugares que no necesariamente son parte de una región metropolitana, pero que al igual que éstas, ofrecen ventajas competitivas apetecibles para el capital. En consecuencia, la territorialidad de esta región virtual debe interpretarse siguiendo los derroteros realizados por las empresas en tanto provisión de insumos de todo tipo, producción segmentada y comercialización de productos finales. En este sentido, la territorialidad estaría definida por un lógica vertical (la del sector) y no por una lógica horizontal (la del territorio de la región metropolitana), puesto que este territorio queda dependiente de la decisiones sectoriales al momento de conformar esta región virtual que por su reticularidad toma forma a través de flujos de materiales, información, capitales y mano de obra. 
Estos flujos son direccionados por las empresas, que como agentes sociales construyen una territorialidad que se apropia de cuanta cosa tenga valor para su juego en el espacio de los lugares. Así, cada empresa construye socialmente su propia territorialidad, y en esa construcción fragmenta los territorios en los cuales se asienta -esto al menos fue lo ocurrido en la RMC.

De este modo, la región virtual de la industria automotriz se configura de manera contractual entre empresas de diferentes tamaños que pactan contratos para proveer a la gran empresa red: la ensambladora automotriz. Asimismo, esta región tiene una estructura complementaria en la medida que los territorios componentes de ella funcionan sincronizadamente en red y en cadena para obtener su producto final. Obviamente, la construcción de la región es selectiva, porque son las empresas las que deciden y seleccionan la localización o no de un establecimiento productivo; de allí que su espacialidad es discontinua porque se apropian de las ventajas de los lugares, que aunque distantes, son unidos virtualmente por las tecnologías de la información y las comunicaciones. Además, las decisiones locacionales responden a una planificación táctica acorde a los intereses empresariales, lo que deviene en un tipo de proyecto regional de corte coyuntural, es decir, dura mientras la rentabilidad sea la esperada; cuando ésta disminuye, la ideología de la competencia lleva a que se busque otro lugar para su funcionamiento, por lo que su temporalidad es pactada y su descentralización es funcional a las estrategias empresariales de segmentación productiva y organización flexible.

\section{Metodología de análisis para el abordaje de la producción flexible en un contexto territorial}

La metodología propuesta presenta la estructura conceptual sobre la que se sistematizó el conjunto de datos empíricos recopilados en torno al leading case. Las interrelaciones entre los conceptos podrán apreciarse con mayor claridad en la Figura 2, donde éstos se sistematizan, ordenan y jerarquizan.

La producción flexible, característica distintiva del régimen de acumulación posfordista recién implementado en la década del '90 en Argentina, muestra en el caso de la industria automotriz dos correlatos inmediatos en el ámbito de la línea de producción: flexibilidad organizacional y flexibilización laboral. La flexibilidad es la práctica productiva y la flexibilización el efecto de dicha práctica sobre un mercado que denominamos mercado de trabajo flexible.

La flexibilidad organizacional implica un cambio en la lógica de gestión, la cual se expresa en torno a tres cuestiones: (a) conformación de un territorio en red a partir de la constitución de empresas red y redes de empresas, observándose procesos como abastecimiento mediante sistema just in time, kam bam y tradicional con depósito en tiempo reducido, terciarización de productos y servicios y externalización de riesgos, a partir de los cuales emerge una reaglomeración just in time; (b) trabajo polivalente con funcionamiento en equipos de trabajo mediante organización en células productivas; permanente rotación en los puestos de trabajo (polivalencia), horizontalización de jerarquía; y capacitación constante y fomento del involucramiento productivo del trabajador en su tarea, estrategias que, unidas al uso de las tecnologías de la información y las comunicaciones (TIC), contribuyen a flexibilizar el mercado de trabajo; y (c) líneas de producción flexible que suponen reconversión tecnológica en procesos y productos mediante la asistencia de las TIC.

Por otra parte, la flexibilización laboral se traduce en precariedad laboral, dada la nueva normativa marco que con la firma de "modernos" convenios colectivos de trabajo, legaliza la flexibilización y propicia la desregulación del mercado de trabajo. Esta "regulación" se materializa en baja de salarios, aumento de las horas de trabajo, pérdidas de conquistas laborales e inseguridad en la permanencia en el puesto de trabajo, incertidumbre que tiene lugar ante las situaciones de suspensiones, despidos y despidos encubiertos. Asimismo, otro elemento que no hay que perder de vista son las formas de contratación de la fuerza de trabajo. Se observan dos modalidades: el empleo directo y el indirecto. Dentro del primero se mantiene el tipo de empleo permanente y emergen el empleo temporal por contrato y el empleo suspendido; dentro del segundo, modalidad distintiva de la flexibilización, asoman el em- 


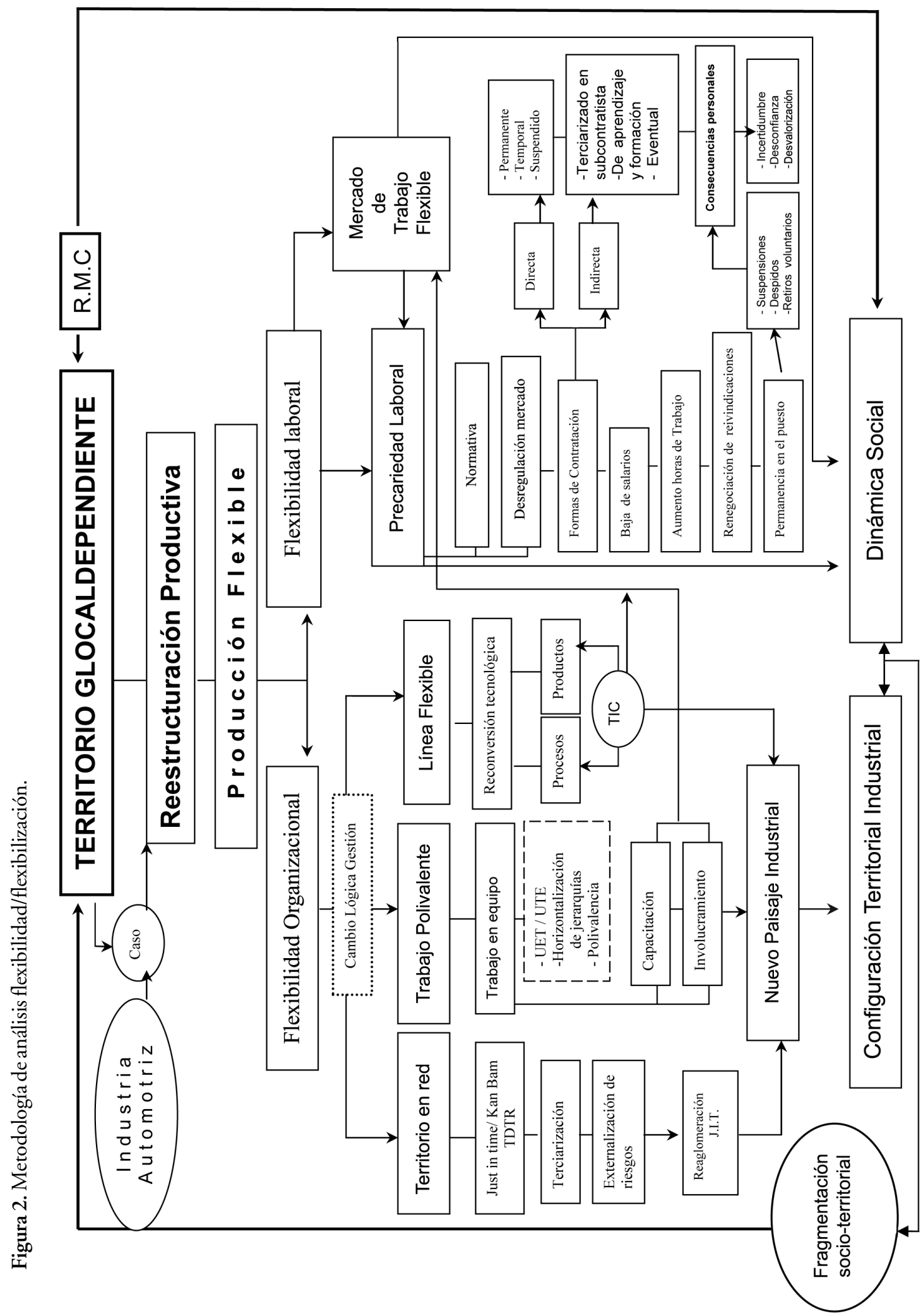


pleo terciarizado en empresas subcontratistas de productos y servicios, el empleo de aprendizaje y formación y el empleo eventual por agencia.

En definitiva, la flexibilidad organizacional da cuenta de la emergencia de un nuevo paisaje industrial observable en plantas ensambladoras automatizadas y robotizadas, reducidas en tamaño con relación a la fábrica fordista y conectadas por flujos de información y materiales con empresas subcontratistas localizadas preferentemente en parques industriales en las adyacencias, o ubicados en un radio cercano. En ambos casos, la circulación es permanente y sincronizada mediante un sistema de logística que llega justo a tiempo para asistir a una línea de producción donde cada equipo de trabajo está capacitado para tomar decisiones y asumir responsabilidades con un criterio de calidad y eficiencia que los convierte en trabajadores polivalentes. Así constituido, este paisaje deviene en una nueva configuración territorial industrial. Esta forma se relaciona dialécticamente con el contenido resultante de una nueva dinámica social, producto de la precariedad laboral en que deriva la flexibilización laboral. Esta relación dialéctica da cuenta de un proceso de fragmentación socio-territorial, que en el caso del $\mathrm{RMC}-\mathrm{y}$ en el contexto de la reestructuración productiva de la década del '90- deviene en la emergencia de un "territorio glocaldependiente".

\section{El caso Daimler-Chrysler}

\subsection{Flexibilidad organizacional}

\subsubsection{Territorio en red: nueva lógica localizacional}

Chrysler es una de las grandes empresas transnacionales dedicadas al rubro automotriz que se instala en la RMC a mediados de la década del '90. Esta transnacional no tenía antecedentes de localización en Córdoba, aunque se debe recordar que hasta la década del '70 la empresa tuvo instalaciones en Argentina, en la Provincia de Buenos Aires, retirándose del país por no resultarle en aquel momento un mercado apetecible. Eso sí, al mismo tiempo que abandonaba el mercado argentino, conservaba sus instalaciones en Brasil, donde se presentaba un mercado de mayores dimensiones que el primero.
A comienzo de la década del ' 90 , a escala mundial Chrysler era una empresa en crisis por falta de renovación de modelos y precios no competitivos. Se plantea entonces el desafío del cambio para adaptarse a nuevos tiempos. El cambio y la innovación llegaron de la mano de la inyección de capitales de nuevos accionistas y a través del desarrollo de nuevos modelos. Entre éstos cabe destacar el modelo Caravan, de amplia aceptación en el mercado europeo, y el Cherokee, de gran éxito en el mercado de Estados Unidos, los cuales permitieron el resurgimiento de la firma y el diseño de una nueva lógica localizacional para encarar nuevos negocios. Así, en 1999 se fusiona con la firma alemana Daimler-Mercedes Benz. De alguna manera, esta estrategia de fusión da cuenta de que más allá de los cambios operados, la firma, con sede en Detroit, continuaba adoleciendo de problemas financieros.

A escala de Córdoba, la integración jurídica de ambas compañías recién se inscribió formalmente en el mes de mayo de 2000. La fusión inicialmente no tuvo fuertes repercusiones en Córdoba, más allá de la instalación de un cartel con el nuevo nombre de la empresa (Daimler-Chrysler), según aseguraban los trabajadores entrevistados. Pero conforme pasaron los meses la fusión no escapó al principio general que sostiene, parafraseando el principio de Arquímedes, que toda fusión entre empresas experimenta un empuje hacia la desocupación, cierres y traslados de instalaciones, proporcional a la importancia de las empresas fusionadas. Efectivamente, en diciembre de ese año los rumores de despidos y cierre eran cada vez mayores, así como las desmentidas al respecto. Pero una reunión a escala mundial de la firma fusionada realizada en enero del 2001 dio la última palabra: el cierre de la planta Córdoba junto al cierre y traslado de otras instalaciones en el mundo, con los consiguientes despidos que la medida implicó: en todo el mundo se despidieron 26.000 empleados. Córdoba no fue el único territorio afectado por la decisión a escala mundial. En Estados Unidos se eliminó un turno en tres plantas (Belvedere III, Jefferson North y ToledoII, Ohio), se redujo producción en la planta de Newark y en la planta de Detroit se trasladó una línea. En México se cerró la planta de Toluca y se trasladó la producción de la planta de Lago Alberto a la planta de Saltillo. En Brasil, se interrumpió la producción en la planta de 
Campo Largo, Paraná, hasta nueva evaluación de resultados.

Sin embargo, antes de llegar a este desenlace retomemos lo acontecido con anterioridad a la fusión. La conformación del MERCOSUR se había presentado a mediados de la década del 90 ' como un buen negocio para la empresa Chrysler, sobre todo si localizaba plantas en Brasil y Argentina; cumpliendo esta condición, pactada en el Régimen $\mathrm{Au}$ tomotriz, además de producir para el mercado regional, podría importar con muy bajos aranceles otros modelos producidos en otras filiales extra región. Eso fue lo ocurrido con los modelos de vehículo como el Neon, el Caravan, el Dakota y el Stratus. Esta situación tentó a la firma norteamericana, pues podría comercializar sus vehículos producidos en otras plantas del mundo con precios competitivos tanto en Brasil como en Argentina. De hecho, esto se pudo constatar en el caso de Argentina. La empresa importó y distribuyó los modelos mencionados mediante una serie de concesionarios localizados en distintos puntos del país ${ }^{4}$.

Teniendo en cuenta esta buena perspectiva del nuevo mercado regional emergente del MERCOSUR, y contando ya con plantas de producción en Brasil, Chrysler arriba nuevamente al país en 1996 luego de veinte años de ausencia. Instala sus oficinas de administración y comercialización en Buenos Aires, y el área de producción la localiza en la RMC. De una serie de entrevistas mantenidas con directivos de la empresa se resalta que primaron en esta decisión las excepciones impositivas y los incentivos fiscales ofrecidos por el gobierno de la provincia, aunque no del gobierno municipal. Asimismo, la empresa valoró la abundancia y calificación de la mano de obra así como su escaso nivel de conflictividad, la existencia de economías de escala, la presencia de universidades y escuelas técnicas como también la existencia de servicios a la producción y de infraestructura vial que le garantizaban su acceso

\footnotetext{
${ }^{4}$ Cuestión que continuó haciendo luego del cierre de la planta Córdoba porque contaba con la planta Mercedes Benz localizada en Buenos Aires, la cual -después del cierre en Córdoba- quedaba como referente de la empresa fusionada en el país. Digamos que nuevamente ganaba la empresa y perdía el territorio; la empresa ahorra en costos operativos y al territorio se le suman nuevos desocupados y unas cuantas pymes locales sin clientes.
}

al MERCOSUR. En síntesis, primó para la localización en Córdoba el valor de uso complejo de la ciudad por encima de las excepciones impositivas que podría haber brindado el municipio.

En 1997 Chrysler termina la construcción de una planta totalmente nueva en Córdoba, en el cuadrante sudeste de la ciudad; emplazada en el área denominada Ferreyra, ocupaba suelo de carácter exclusivo para uso industrial. Se instala una planta de bajo costo de mantenimiento y bajo volumen de producción, en la medida que la cantidad de vehículos que salían de línea por día oscilaba entre veintidós y cuarenta, según la demanda de mercado. Los directivos de la firma se apresuraron a indicar que la producción era significativamente reducida en relación a lo producido por otras filiales, pero toda vez que ello fuese necesario, se podría ampliar la capacidad. De todos modos, es preciso señalar que durante 1997 y 1998 la capacidad productiva total de la planta estuvo utilizada sólo en un $20 \%$ y $40 \%$ respectivamente; así, en 1997 se producían veintidós vehículos, en 1998 cuarenta y en 1999 la producción bajó nuevamente a veinte vehículos por día. La planta se especializó en el ensamblaje de modelos de 4x4: el Jeep Cherokee y el Jeep Gran Cherokee, este último reemplazado a partir de 1999 por una versión modernizada. Todos los productos de la empresa se dirigieron a un segmento de mercado de alto poder adquisitivo.

La estrategia territorial seguida por Chrysler en el caso de Argentina es una integración vertical con estructura en racimo. Dentro de la estrategia global de la empresa, la planta localizada en Córdoba tenía como objetivo inicial ensamblar y proveer vehículos al MERCOSUR. Originariamente la filial se instaló con la idea de que un $70 \%$ de la producción tuviese como destino Brasil y sólo un 30\% Argentina. En los dos primeros años de producción, el mercado respondió a las expectativas de la empresa; incluso en 1998 la producción se duplicó, no así en 1999, cuando cayó por debajo de lo producido en el año 1997 (Figura 3).

Las razones de la caída son atribuidas por la empresa a la crisis y devaluación en Brasil, lugar donde quedó un importante stock sin vender. A pesar del mal trago, la empresa preveía en ese momento que la situación mejoraría en los próximos tres años, tanto 
Figura 3. Producción diaria de Chrysler Córdoba.

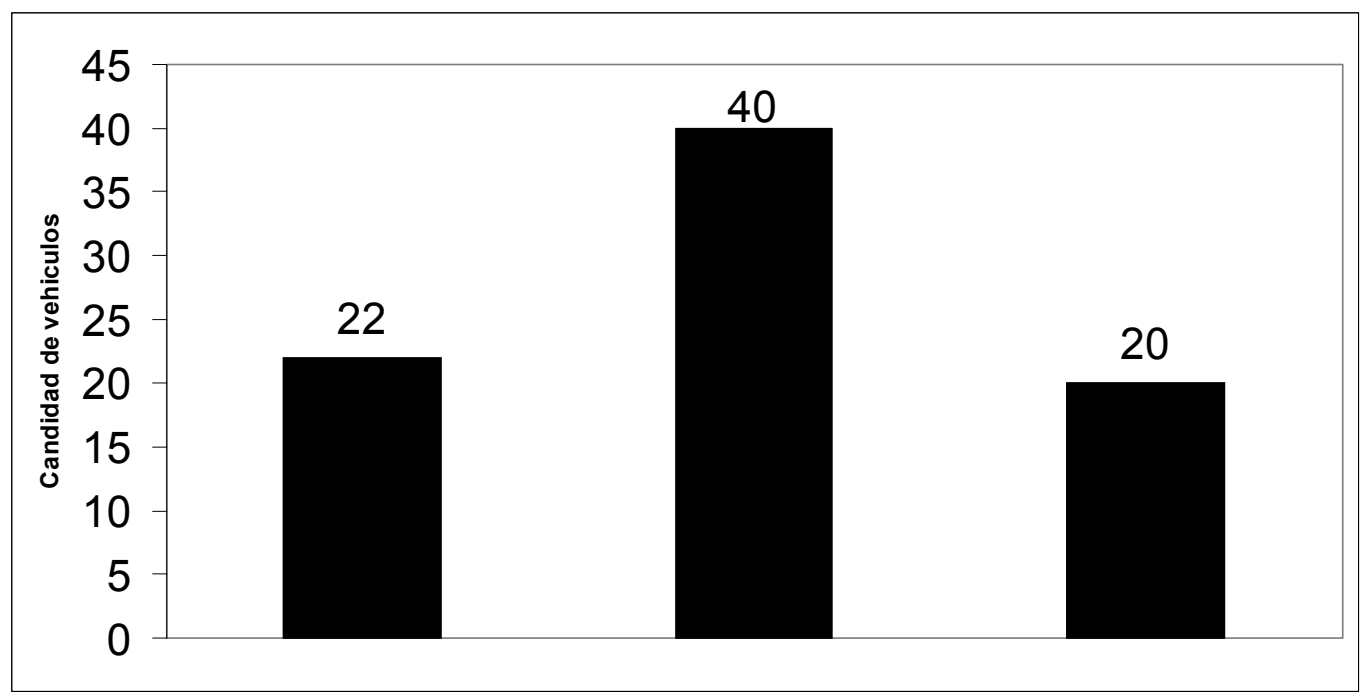

Fuente: elaboración propia sobre la base de información de entrevistas.

por un aumento de ventas en el mercado nacional como por las exportaciones que se esperaban con destino al MERCOSUR.

La planta Córdoba comenzó con un sistema de producción flexible con la adopción del sistema de aprovisionamiento just in time, en lo que respecta a proveedores locales, y con sistema de aprovisionamiento por kit, en relación a proveedores externos. Los vehículos ensamblados tuvieron un alto porcentaje de autopartes importadas de las plantas de Estados Unidos y Canadá. El Régimen Automotriz vigente hasta 1999 exigía un 40\% de autopartes producidas en el país. Para cubrir ese porcentaje, la empresa recurrió a una estrategia subrepticia: se asoció con empresas locales, las que recibieron autopartes importadas, y con la adición de mano de obra para su armado y/o presentación las proveyeron terminadas a Chrysler. De este modo, las autopartes adquirieron el carácter de nacional, cuando en realidad se trataba de elementos importados. Así, por ejemplo, la adición de un forro de cuero para cubrir una goma transformó a esta autoparte en un componente nacional. Cabe aclarar que a partir del nuevo Régimen Automotriz firmado en el año 2000, el requerimiento de autopartes nacionales se redujo al $30 \%$, lo que podría estar indicando, lobby mediante de la cámara que agrupa a las ensambladoras (Adefa), el blanqueo de una situación ya de hecho.
La empresa estableció desde su arribo una serie de contratos fijos con sus proveedores, los que debieron certificar normas de calidad y estar dispuestos a asociarse mediante joint ventures con proveedores localizados en Estados Unidos. Asimismo, estos proveedores locales fueron asistidos por el departamento de desarrollo de proveedores para garantizar la provisión a línea justo a tiempo mediante sistema informático y de telecomunicaciones. Es notable destacar que en este cometido la empresa argumentó tener problemas por la escasa reconversión del sector autopartista local, lo cual estaría indicando que las pocas empresas que se integraron al circuito de provisión de las ensambladoras tampoco eran de la total satisfacción de la transnacional automotriz; esto le permitió justificar la necesidad de importaciones, siendo esto en realidad uno de los fines de su localización en Córdoba (recordemos que el MERCOSUR les permite a las transnacionales ubicar sus remanentes de otras filiales en el mundo).

La otra parte del aprovisionamiento a línea se hizo mediante kits importados. Cada uno traía autopartes para armar 24 ó 48 vehículos de determinado modelo. La empresa encargada de la logística era la que recibía, abría, clasificaba, separaba y enviaba cada pieza al lugar correspondiente, con el previo asesoramiento del área de ingeniería de Chrysler. El volumen de producción se calculaba 
por hora y era asistido por computadoras que secuencian el aprovisionamiento a la línea.

El outsourcing diseñado por la empresa para la provisión de autopartes también se efectivizaba en los servicios directamente relacionados con el vehículo (logística, control de calidad y validación dinámica de vehículos, recepción y distribución a concesionarios de los productos finales), así como en los servicios a la planta y al personal (mantenimiento, seguridad, limpieza, alimentación, salud y contrato eventual de personal).

\subsubsection{Línea flexible: innovaciones y reconversión tecnológica}

En el caso de Chrysler, a diferencia de Fiat y Renault, no se puede utilizar el término reconversión para considerar la implementación de la línea de producción flexible. En este caso lo más adecuado es emplear el término propuesta tecnológica, ya que Chrysler se instala por primera vez en la RMC sin una historia previa en el lugar. No debemos confundirnos, pues en todos los casos las formas tecnológicas son similares con implementación de líneas flexibles de producción. Las diferencias radican en las particularidades idiosincrásicas de cada empresa, y en que Fiat y Renault iniciaron el proceso con una historia en línea de producción rígida lo que supuso un camino distinto al recorrido por Chrysler, que sin historia previa en el lugar inició sus actividades con líneas flexibles; esto es importante destacarlo en la medida que facilita la implementación de prácticas productivas flexibles en sus trabajadores.

En relación a la propuesta tecnológica se debe señalar que las instalaciones construidas en los predios de Ferreyra respondían a una planta totalmente manual, con solo un robot asistiendo a la producción. Se aplicaban sistemas CAD/CAM en la planta de pintura y sistemas informáticos para obtención de datos y regulación automática del proceso de producción en el conjunto de la planta, existiendo algunas herramientas neumáticas como por ejemplo, el prain que arma la estructura, y luego la soldadura se hace en la línea.

La utilización de esta tecnología y el tipo de propuesta organizacional de la producción, garantizaba según la empresa, y por ese momento, calidad y competitividad en el segmento de mercado escogido tanto para el mercado nacional como para el Mercosur. Es por esto que no se preveían inversiones significativas para los próximos años en materia de tecnología. Por otra parte, se aducía que mientras la planta continuase con bajo volumen de producción no se justificaba una mayor automatización. La fábrica se componía tan solo de tres plantas: una de pintura, otra de chapa y otra de chasis, tapicería y final. Asimismo contaba con una planta depuradora de residuos que garantizan el tratamiento ambiental del agua utilizada por la planta.

\subsubsection{Trabajo polivalente: lógica de gestión y cambios laborales}

Desde el punto de vista organizacional cada una de las plantas tenía ingenieros de producción y un group lider. Los primeros se abocaban a temas de diagramación de la producción y eran los facilitadores del área a su cargo. Los segundos, manejaban a los operarios garantizando la salida de los productos. La estructura se termina de componer por las células productivas, es decir por teams a cargo de un líder. Cada grupo constituye una célula productiva formada por 5 ó 6 personas. A lo largo de la línea existen tantas células como la programación de la producción así lo requería. Cuando la producción aumentaba se recurría a la contratación de trabajadores eventuales por medio de agencias de empleo.

Este tipo de organización permitía la constitución de una línea flexible que, asistida por computadoras, ensamblaba vehículos de características particulares proporcionadas en tiempo real por los concesionarios según lo solicitado por los clientes. Cuando se presentaba un problema en la línea de ensamblado, el líder de cada team asistía a los operarios de la célula y en caso de ser necesario, era política de la empresa detener la línea para solucionar el problema. Para esto se entrenaba a los trabajadores mediante cursos internos en la empresa, relativos a lo que llamaban como "clínica de aprendizaje”. El objetivo de los cursos era el desarrollo de la capacidad de resolución de problemas dentro de la vía escogida por el trabajador para tal fin. La intención era lograr autonomía en el trabajador y ayudar a su polivalencia para rotar por diferentes puestos de trabajo. No obstante, lo que no se dice es que cada trabajador, cuidando la calidad y eficacia de los pro- 
cesos, está controlando y exigiendo a sus compañeros sin ser retribuido de manera extra, por un trabajo que antes realizaba una persona dedicada a tal fin y que con el nuevo planteo quedó fuera de la ecuación capital-empleo.

La planta Chrysler se inició con una serie de ventajas en cuanto a su propuesta laboral en relación a la reconversión que sí debieron realizar las otras ensambladoras automotrices localizadas en la RMC al tener una larga historia laboral sobre sus hombros. Aquí no se debieron reconvertir viejas prácticas entre el personal ocupado, ni negociar con el sindicato (SMATA); por el contrario, la empresa realizó un modelado del perfil de operarios y empleados según los requerimientos del sistema de producción flexible. Para esto se llevó a cabo un mix en la selección del personal, entre personal no capacitado en el tema automotriz y sin experiencia y el personal proveniente de otras empresas automotrices como Fiat, Renault y General Motors, apropiándose en este último caso del know how adquirido por esos trabajadores en esas empresas. Asimismo, es de hacer notar que la edad promedio requerida era de veinticuatro años y se solicitaba escolaridad secundaria y universitaria de manera excluyente.

Este modelado del personal se realiza mediante una considerable inversión en capacitación permanente por parte de la empresa con sus trabajadores, tanto en Argentina como en el exterior. Se rotaban grupos de operarios y empleados por otras filiales de Chrysler en Austria, Estados Unidos, Brasil y Venezuela. Esta práctica se llevó a cabo desde un año antes de estar construida la planta. La intención era reforzar el modelo organizacional basado en el trabajo por células productivas como en la consideración que el empleado capacitado y polivalente era una ventaja competitiva para la empresa. Luego de la puesta en marcha de la planta la capacitación continúa tanto en el interior de la planta como llevando gente afuera.

El sistema de producción flexible implementado por Chrysler desde el punto de vista laboral tiene dos características esenciales: la polivalencia y el involucramiento. En otros términos, el operario o un empleado polivalente era aquel que no sólo debía tener una función específica por tiempo indeterminado, sino que por el contrario y según su capacita- ción constante, debía ser capaz de rotar por diferentes áreas de la planta.

\subsection{Flexibilización laboral}

\subsubsection{La precariedad laboral en un mercado de trabajo flexible}

Bajo la premisa de la polivalencia y la delegación de responsabilidades a los equipos de trabajo, la empresa Chrysler organizó a su personal afectado a la producción en dos clases: operarios y empleados. En ambos casos se propiciaba el involucramiento, no obstante que el alcance de los salarios era diferente tanto en el monto a cobrar como en la negociación de los mismos.

Los operarios estaban organizados en cuatro categorías a las cuales se accedía a través del logro de mayor polivalencia. Asimismo, ésta se conseguía con capacitación y rotación por diferentes puestos en la línea. En el caso de los operarios, el involucramiento se pretendía mediante un sistema de premios y conformación del salario a través de: (a) un salario básico fijo por mes según categoría: de $\$ 470$ para la categoría uno, de $\$ 670$ para la categoría dos, de $\$ 720$ para la tres y de $\$ 900$ para la categoría cuatro; (b) un salario variable con una retribución de $12,5 \%$ por logro de objetivo de célula y otro $12,5 \%$ por cumplimiento de objetivo de empresa; $y$ (c) un salario no remunerativo consistente en ticket para compras en supermercados y restaurantes que rondaba los $\$ 270$ al mes.

Es de notar que casi no existían operarios con categoría uno, por lo que un salario de bolsillo, considerando como base la categoría dos, y teniendo en cuenta el salario fijo y el monto no remunerativo, era aproximadamente de $\$ 940$ a lo que se debía sumar el salario variable. Comparativamente era considerable la diferencia con el salario ofrecido por la empresa Fiat donde el salario de bolsillo por mes era de aproximadamente $\$ 500^{5}$. Esta diferencia era la que hacía que los operarios de Chrysler se encontrasen más conformes al compararse con sus compañeros de la ensambladora vecina. Inclusive después del cierre de la planta, un trabajador de

${ }^{5}$ Los salarios de ambas empresas se calculan sin considerar el pago de horas extras. 
Chrysler señala el "buen trato y la consideración de la empresa hacia los trabajadores es muy rescatable en relación con la que pasaron y pasan los muchachos de Fiat". Esta afirmación es ponderable en la medida que la estaba expresando un trabajador despedido y coincide con otras opiniones que pueden recogerse entre los trabajadores. De todos modos, señala el grado de alienación del trabajador que pasando a una zona de desafiliación laboral (Castel, 1997), aún continúa reconociendo méritos a la empresa.

Ahora bien, retomando la cuestión salarial, es importante indicar que los operarios de Chrysler se regían por un convenio colectivo de trabajo firmado entre la empresa y el SMATA, sindicato que agrupaba a los operarios de planta, al cual adherían solo el $75 \%$ de los trabajadores. El otro $25 \%$ no tenía afiliación sindical. Este convenio tenía una duración de cuatro años a contar a partir de 1996. Como se observa aquí también funcionó un convenio colectivo por empresa y no por sector.

Por su parte, los empleados no se dividían en categorías ni entraban por convenio, sino que negociaban su salario de manera individual con la empresa, con lo cual no existía intermediación del sindicato. Entre los empleados se encontraban ingenieros y técnicos especializados que realizaban tareas de tipo organizativo. Sus salarios oscilaban entre los $\$ 1800$ y los $\$ 2500$. Estas diferencias estaban dadas por la experiencia y antigüedad en la tarea que se demandaba y por la capacidad de negociación individual del empleado, aunque los entrevistados señalan que el margen de negociación no era muy amplio. Lo que sí se ha podido constatar es que a diferencia de Fiat existía en Chrysler un mercado interno de trabajo, al estilo de la empresa japonesa (Coriat, 1998). Se realizaban búsquedas internas de personal y quien ganaba dicha búsqueda accedía a puestos más altos y más cotizados.

Se debe agregar que la empresa recurría al contrato de empleo eventual mediante la solicitud de dicho personal a terceras empresas dedicadas al tema. Esto ocurrió sobre todo en 1998, año en el cual se duplicó la producción y fue necesario reforzar el trabajo con mano de obra eventual. Los salarios de este personal eran más bajos que el del operario polivalente de contrato permanente. Esta metodo- logía le permitió a Chrysler mantener su planta fija de personal sin despidos desde su instalación, con lo cual la flexibilización y precariedad laboral se terciarizaron puesto que quienes despedían al personal cuando la producción bajaba era la empresa de empleos y no Chrysler. Esta estrategia permitió reducir cualquier tipo de conflictividad al interior de la planta así como evitó todo tipo de prácticas reivindicativas por parte de los trabajadores. Esta falta de prácticas reactivas tal vez explique por qué los trabajadores permanentes no tuvieron ningún tipo de reacción en contra de la empresa al momento del cierre de la misma.

En este sentido, se pudo constatar que el ambiente de trabajo dentro de la planta era de conformidad con la patronal sobre todo en lo que a empleo directo se refiere; en cambio, sí se evidenciaba malestar en los trabajadores eventuales que cobraban menos y eran la variable de ajuste cuando la producción disminuía y se debía reducir personal.

Tanto de las visitas realizadas a planta, como de las entrevistas mantenidas con operarios y empleados surge que los trabajadores se sintieron valorados en su trabajo. Esta apreciación surgió siempre en comparación con el trato recibido por los trabajadores en otras empresas ensambladoras localizadas en la RMC, sobre todo de la comparación con Fiat. Si bien se debe convenir que los salarios no eran altos y el personal reconoce esto, sobre todo a nivel de operario, no se escuchó la crítica generalizada que sí se observaba en Fiat, empresa en la cual los trabajadores constantemente se quejaban de la subvaloración sufrida y de los bajos salarios asignados.

Digamos que en el contexto de alto desempleo, como el que paulatina y sistemáticamente se instauró en Argentina en la segunda mitad del quinquenio de los años 90', la alienación alcanzada por los trabajadores fue tal, que no pudieron evaluar sus reales condiciones de trabajo. Si bien es cierto que la empresa dispensó cordial trato a sus trabajadores, la relación laboral no estuvo exenta de suspensiones con cobro de salario al $75 \%$ en varias ocasiones durante los años 1999 y 2000. Además la incertidumbre comenzó a desgastar el ánimo de los trabajadores ante los rumores de cierre, aun cuando los directivos salían al cruce de esos dichos y tranquilizaban al per- 
sonal. Pero la realidad fue que, con una corta vida de producción en Córdoba, la empresa cerró a comienzos del año 2001 y sus líneas de ensamble fueron trasladadas a una nueva planta que operaría en China. De este modo se efectivizó otro proceso concreto de migración empresarial.

Cabe preguntarse qué quedó de este ensayo de reindustrialización en Córdoba en relación con la empresa Chrysler. De las instalaciones, solo quedó un gran galpón que yace como monumento de lo que quiso ser la Detroit sudamericana, tal como pretenciosamente calificaron a la ciudad, tanto el gobierno como la prensa en aquellos años en que las empresas arribaban a Córdoba. De los trabajadores sólo quedó el recuerdo y una promesa de traslado a la planta de González Catan de la firma Mercedes Benz en Buenos Aires, propuesta que solo fue tomada por nueve trabajadores. Los 180 trabajadores restantes pasaron a engrosar la larga fila de desocupados que ya poseía el sector. De la red de empresas que conformaron el espacio industrial de ésta, es decir, de las proveedoras de Chrysler localizadas en Córdoba, sólo quedaron más trabajadores suspendidos y desocupados. Aquí cabe mencionar que a excepción de unas pocas empresas de capitales localesdos o tres- el resto de las proveedoras eran transnacionales que suspendieron $y / o$ finiquitaron sus actividades.

Pero como no todos los territorios son impactados de igual manera por esta lógica de la glocalización, es importante traer a relato un dato que da cuenta de cómo el capital contribuye a la división territorial del trabajo. En efecto, mientras en un ámbito periférico como Córdoba caía una inversión por una decisión tomada a muchos kilómetros de ese territorio, la corporación Daimler-Chrysler anunciaba nuevas inversiones, por cierto millonarias, en I+D para desarrollar tecnología de pilas de combustibles para propulsar autos que circularían a hidrógeno en los ámbitos centrales.

\section{Aproximaciones finales}

En efecto, las empresas a través de sus estrategias y lógicas de gestión construyen una territorialidad que excede largamente el territorio donde se localizan, por ejemplo el de una región metropolitana. En este discurrir los territorios son cruzados por lógicas ajenas y lejanas pero que de hecho terminan constituyéndose en lógica propia y afectan la lógica cercana del hombre cotidiano. Este proceso deviene en inclusión para unos pocos y en exclusión para muchos. Esto en términos económicos es igual a crecimiento sin desarrollo pues emerge un territorio cruzado por lógicas lejanas y ajenas en el cual no todos los agentes sociales participaron con igual fuerza para conseguir su reproducción. Así la llegada y migración de Daimler-Chrysler es solo un ejemplo que puede sumarse al de otras transnacionales que se localizaron en la RMC y que siguieron igual camino, como Delphi Packard, Maxion, Hartam Motive, General Motors, entre otras.

En este contexto, el MERCOSUR y principalmente algunas de sus ciudades "ganadoras", ávidas de inversiones, abrieron sus puertas a las empresas transnacionales, poseedoras de los capitales que necesitaban para "crecer". De este modo, y bajo una fuerte retórica neoliberal, paulatinamente a lo largo de la década de los 90' se ha conformado un territorio donde lo global hundió sus raíces en lo local y el territorio quedó dependiente de las estrategias convergentes de dos de los agentes portadores de lo global y lo local, es decir, de empresas y gobierno respectivamente. De las primeras queda clara su lógica, de los segundos, solo decir que su lógica responde a la reproducción de corto plazo electoral.

La primera implicancia de la emergencia de este territorio es una gran paradoja: a la vez que lo global penetra en las estructuras territoriales históricas locales inyectando capitales, las sociedades locales se sumergen en el crecimiento para unos pocos y en la pobreza para la mayoría, no sólo por el desempleo, sino también por las condiciones precarias de quienes aún conservan sus puestos de trabajo con todas las consecuencias socioterritoriales que producen las zonas de desafiliación generadas en la estructura social. Pero ¿̨no era acaso que la inyección de capitales sería la savia vital para que las sociedades emergiesen según el credo neoliberal imperante en los años ' 90 ? En el caso de los ámbitos periféricos esa savia se ha convertido en un veneno letal. Y en este sentido, los llamados mercados emergentes para las transnacionales deberían ser denominados "mercados sumergentes" para el territorio. 


\section{Referencias bibliográficas}

Boisier, S. (1994) "Postmodernismo territorial y globalización: regiones pivotales y regiones virtuales". Ciudady Territorio, 2, 2.

Castel, R. (1997). Metamorfosis de la cuestión social. Buenos Aires: Paidós.

Cecchetto, G. (1988). "Evolución de los asentamientos industriales IKA y FIAT. Su inserción en el espacio urbano cordobés. Un estudio comparado (1955-1968)". Informe presentado al CONICOR. Córdoba.

(1990). "Dinámica urbana de las áreas industriales del sur de la ciudad de Córdoba (1970-1980)". Informe presentado al CONICOR. Córdoba.

Coriat, B. (1998). Pensar al revés. Trabajo y organización en la empresa japonesa. México: Siglo XXI.

Gatto, F. (1990). "Cambio tecnológico neofordista y reorganización productiva. Primeras reflexiones sobre sus implicancias territoriales". Alburquerque, F. et al., Revolución tecnológicay reestructuración productiva: impactosy desafios territoriales. Buenos Aires: Grupo Editor Latinoamericano.

INDEC (1999). La producción industrial argentina en los años 90. Buenos Aires: Ministerio de Economía, Obras y Servicios Públicos, Secretaría de Programación Económica y Regional - INDEC.

Nazareno, M. (1991) "Comportamiento empresarial en la pequeña y mediana unidad productiva metalmecánica de la provincia de Córdoba 1975-1990" (tesis inédita). Córdoba: Escuela de Historia, Universidad Nacional de Córdoba.

Novick, M. \& G. Yoguel (1998). "Espacios emergentes en la industria automovilística internacional: algunas evidencias del caso argentino".
Ponencia presentada en el $4^{\circ}$ Congreso Nacional de Estudios del Trabajo. Organizado por ASET Asociación Argentina de Especialistas del Trabajo. Buenos Aires, 4 al de 6 de noviembre. Méndez, R. \& I. Caravaca (1996). Organización industrialy territorio. Madrid: Síntesis.

Rifkin, J. (1996). El fin del trabajo: nuevas tecnologias contra puestos de trabajo. El nacimiento de una nueva era. Barcelona: Paidós.

Sack, R. D. (1986). Human territoriality: its theory and history. Cambridge: Cambridge University Press.

Santos, M. (1986). "Espacio y método". Geocritica, 65.

Sennett, R. (2000). La corrosión del carácter. Las consecuencias personales de trabajo en el nuevo capitalismo. Barcelona: Anagrama.

Soja, E. (1997). "El tercer espacio. Ampliando el horizonte de la imaginación geográfica". Geographikós, 8.

Tomadoni, C. (1999). "Estrategias territoriales de empresas terminales automotrices en el marco de la reestructuración industrial. El caso del Área Metropolitana Córdoba”. Ponencia presentada al V Seminario Internacional de la Red Iberoamericana de Investigadores sobre Globalización y Territorio. Toluca, 21-24 de septiembre.

(2000). "Impactos territoriales de la reestructuración industrial del sector automotriz en el Área Metropolitana Córdoba" (tesis inédita). Andalucía: Universidad Internacional de Andalucía.

(2004). "Production flexible et précarité du travail sur un territoire 'glocaldépendant'. Le cas l'entrepise automobile Renault Argentine”. Annales de Géographie, 635. 